\title{
The Optimal Level of International Reserves for Emerging Market Countries: \\ Formulas and Applications
}

Olivier Jeanne and Romain Rancière 



\title{
IMF Working Paper
}

Research Department

\section{The Optimal Level of International Reserves for Emerging Market Countries: Formulas and Applications}

\author{
Prepared by Olivier Jeanne and Romain Rancière ${ }^{1}$
}

Authorized for distribution by Paolo Mauro

October 2006

\begin{abstract}

\section{This Working Paper should not be reported as representing the views of the IMF.}

The views expressed in this Working Paper are those of the author(s) and do not necessarily represent those of the IMF or IMF policy. Working Papers describe research in progress by the author(s) and are published to elicit comments and to further debate.

We present a model of the optimal level of international reserves for a small open economy that is vulnerable to sudden stops in capital flows. Reserves allow the country to smooth domestic absorption in response to sudden stops, but yield a lower return than the interest rate on the country's long-term debt. We derive a formula for the optimal level of reserves, and show that plausible calibrations can explain reserves of the order of magnitude observed in many emerging market countries. However, the recent buildup of reserves in Asia seems in excess of what would be implied by an insurance motive against sudden stops.

JEL Classification Numbers: F32

Keywords: Foreign Exchange Reserves, Balance of Payments Crises, Sudden Stops, Capital Flows

Authors’ E-Mail Addresses: ojeanne@imf.org; rranciere@imf.org

\footnotetext{
${ }^{1}$ This paper benefited from comments by Herman Kamil, Paolo Mauro, Eric Van Wincoop, and seminar participants at the World Bank, the IMF Institute, and the Inter-American Development Bank. It was completed while Olivier Jeanne was visiting the Department of Economics of Princeton University, whose hospitality is gratefully acknowledged.
} 
Contents

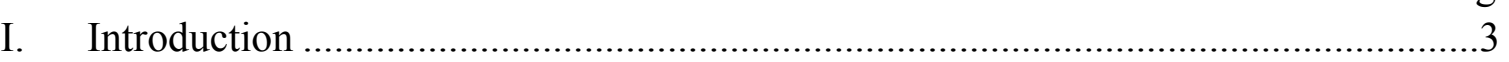

II. Sudden Stops and Reserves: Some Facts ........................................................4

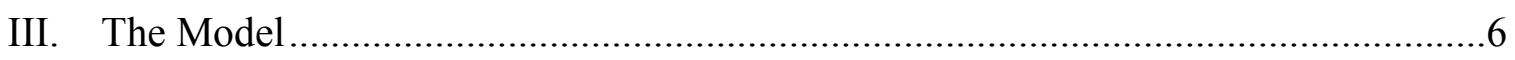

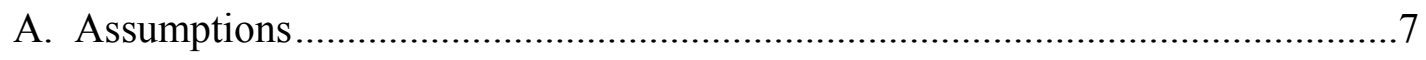

B. A Formula for the Optimal Level of Reserves .............................................. 10

IV. Applications ............................................................................................. 12

A. Benchmark Calibration and Sensitivity Analysis ...........................................12

B. Regional Estimates .................................................................................. 14

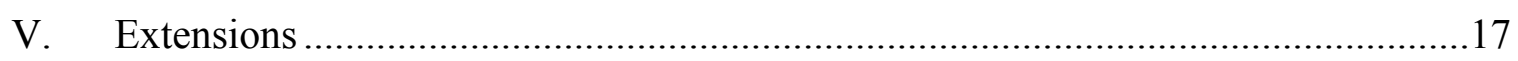

A. Crisis Prevention ...................................................................................... 17

B. Real Exchange Rate Depreciation............................................................... 18

C. Endogenizing the Behavior of the Private Sector ..........................................19

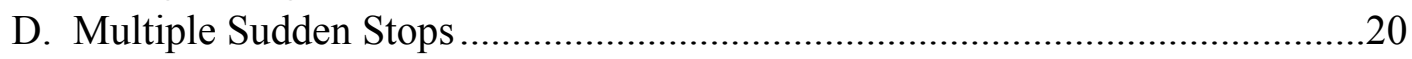

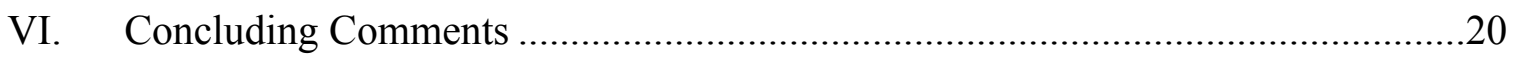

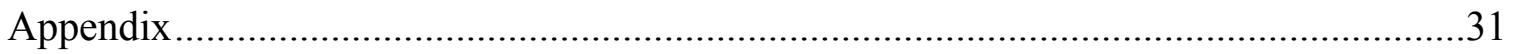

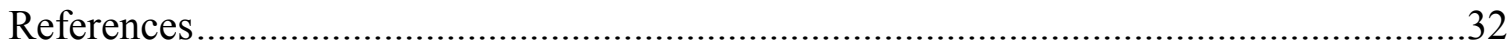

Tables:

1. Countries and Years of Sudden Stops............................................................22

2. Calibration Parameters .........................................................................................23

3. Probit Estimation of the Probability of a Sudden Stop .......................................23

4. Variables Used in Regression Analysis ..............................................................24

5. Changes in Fundamentals and Optimal Reserves .............................................25

Figures:

1. International Reserves as a Share of GDP ....................................................26

2. Domestic Absorption and International Reserves in Sudden Stops, 1980-2003 ....27

3. Domestic Absorption and International Reserves in Sudden Stops in the Model..28

4. The Optimal Level of Reserves: Sensitivity Analysis .........................................29

5. Reserves as a Share of GDP in Asia and Latin America, 1980-2003 ....................30 


\section{INTRODUCTION}

The recent large increase in international reserves, especially in Asia, has generated a debate on the optimal level of reserves for emerging market countries (Figure 1). One view is that reserves have been accumulated as an insurance against the risk of balance of payments crises, which came to be perceived as higher after the 1997-98 Southeast Asian crisis. Against this background, there has been surprisingly little work trying to quantify the level of reserves that can be rationalized in terms of insurance against balance of payments shocks.

The present paper attempts to fill this gap by calibrating a model of the optimal level of reserves for emerging market countries. The model looks at the intertemporal optimization problem of the government in a small open economy that is hit by "sudden stops" in capital flows associated with a fall in output. The main benefit of reserves is to allow the government to smooth domestic absorption in crises. The cost of holding reserves is that they yield a lower return than the interest rate that the government must pay on its long-term external liabilities. We then derive a simple, closed-form formula for the optimal level of reserves, and calibrate it using data on a sample of emerging market countries.

We find that for plausible values of the parameters the model can explain reserves-to-GDP ratios of the order of magnitude observed in emerging market countries over the past decades. For a coefficient of constant relative risk aversion of 2 (a standard value in the real business cycle literature), our model predicts a reserves-to-GDP ratio of 10 percent, which is very close to the average reserves-to-GDP ratio observed in a group of 34 middle-income countries over the period 1980-2003. The model can also account for a significant part of the cross-regional variation in the observed level of reserves, although the discrepancy between the prediction of the model and the data can be large for some periods and regions. In particular, the model does not account for the recent large increase in reserves in emerging market Asian countries.

One contribution of our framework is to provide estimates of the share of the observed stock of reserves that can be justified as an insurance against sudden stops. Countries in the real world could be accumulating less or more reserves than we estimate for reasons that are not in our model. For example, Dooley and others (2004) argue that the reserves buildup in Asia is the unintended consequence of policies that maintain large current account surpluses. Our framework provides a decomposition of the observed level of reserves between one component that can be justified in terms of insurance against sudden stops and one component that cannot (conditional on an assumption on the authorities' risk aversion). This distinction is useful because the public foreign assets that cannot be accounted for in terms of insurance against sudden stops could be managed in a different way than the liquid reserves that are meant to provide such an insurance.

The quantitative literature on reserves has lagged somewhat behind the policy questions that have been raised by the international financial crises of the 1990s. The heyday of the reserve adequacy literature dates back to the 1960s and the 1970s, when the focus was mainly on the current account. The main framework of that literature was the Baumol-Tobin inventory model with fixed costs of depleting and replenishing reserves (see Frenkel and Jovanovic, 1981, and Flood and Marion, 2002, for a recent review). One problem with this approach, 
from a normative point of view, is that some exogenous determinants of the optimal level of reserves - in particular, the fixed costs of depleting and replenishing the reserves - are not micro-founded and are difficult to quantify.

A few recent papers attempt to estimate the optimal level of reserves for emerging market countries that face the risk of sudden stops. Aizenman and Lee (2005) present a three-period stylized model of the optimal level of international reserves based on the Diamond-Dybvig model of banks runs. Caballero and Panageas (2004a,b) develop and estimate a quantifiable model of sudden stops and use it to study practical mechanisms to insure emerging markets against them. They emphasize the benefits of using state-contingent instruments rather than reserves to insure the economy against sudden stops. Garcia and Soto (2004) construct estimates of the optimal level of reserves based on the assumption that the authorities are risk-neutral and accumulate reserves in order to reduce the probability of a sudden stop.

Our framework has a more realistic dynamic structure than Aizenman and Lee's (2005), making it easier to calibrate by reference to the data. It yields closed-form expressions for the optimal level of reserves, whereas the problem can be solved only numerically in the Caballero and Panageas' (2004a,b) framework. By contrast with Garcia and Soto (2004), the main benefit of reserves in our model comes from crisis mitigation rather than crisis prevention. We show how our framework can be extended so as to capture Garcia and Soto's assumption that the probability of sudden stop decreases with the level of reserves.

Maybe for lack of an appropriate quantitative normative framework, policymakers have often used rules of thumb, such as maintaining reserves equivalent to three months of imports ormore recently - the "Greenspan-Guidotti rule" of full coverage of total short-term external debt. The Greenspan-Guidotti rule is a natural benchmark of comparison for our findings because, like our estimates, it is premised on the idea that reserves help countries deal with a sudden stop in short-term external debt flows. We find that the optimal level of reserves suggested by our model is close to the Greenspan-Guidotti rule for plausible calibrations of the model, although it could be higher or lower in principle. We also present an extension of the model with an endogenous probability of sudden stop in which the Greenspan-Guidotti rule and our estimates coincide exactly.

The paper is structured as follows. Section II presents some stylized facts on the behavior of domestic absorption and reserves in sudden stops. Section III develops a model yielding a simple formula for the optimal level of reserves. Section IV presents some calibrations of the model, and compares the model predictions and the data. Section V presents some extensions of the model, and Section VI offers concluding remarks.

\section{SUDDEN STOPS AND RESERVES: SOME FACTS}

This section presents some evidence on the behavior of domestic absorption, output, and reserves in emerging market economies experiencing sudden stops in capital flows. In an open economy, real domestic absorption can be written as the difference between real output and the trade balance: 


$$
A_{t}=Y_{t}-T B_{t}
$$

The trade balance, in turn, can be written,

$$
T B_{t}=-K A_{t}-I T_{t}+\Delta R_{t}
$$

where $K A_{t}$ is the financial account, $I T_{t}$ is income and transfers from abroad, and $\Delta R_{t}=R_{t}-R_{t-1}$ is the change in reserves. ${ }^{2}$ Combining equations (1) and (2) gives a decomposition of domestic absorption as the sum of domestic output, the financial account, income from abroad, and reserves decumulation:

$$
A_{t}=Y_{t}+K A_{t}+I T_{t}-\Delta R_{t}
$$

A sudden stop is an abrupt fall in the capital account, $K A$, which, other things being equal, reduces domestic absorption. The impact of the sudden stop on domestic absorption could be amplified by a concomitant fall in domestic output, $Y$, or mitigated by a fall in reserves, $\Delta R$. For example, reserves can be used to repay external lines of credit that are not rolled over in a sudden stop, alleviating the need to reduce domestic absorption.

We now look how the components of equation (3) behave in observed sudden-stop episodes. In line with Guidotti and others (2004), we identify a sudden stop in year $t$ if the ratio of capital inflows to GDP, $k_{t} \equiv K A_{t} / Y_{t}$, falls by more than 5 percent of GDP relative to the previous year,

$$
\text { sudden stop in year } t \Leftrightarrow k_{t}<k_{t-1}-5 \% \text {. }
$$

We look for sudden stops in a set of 34 middle-income countries over 1975-2003. The countries in our sample and the years in which they had a sudden stop are reported in Table $1 .{ }^{3}$ Reassuringly, our criterion captures many well-known crises (Mexico in 1995; Korea, Thailand, and the Philippines in 1997; Argentina in 2001).

Figure 2 shows the average behavior of domestic absorption and the contribution of the various components on the right-hand side of equation (3) in a five-year event window

\footnotetext{
${ }^{2}$ The financial account was formerly called the capital account (we will use the two terms interchangeably). Domestic absorption is the sum of domestic (private and public) consumption and investment. Equation (2) is derived from the balance of payments equation, $C A_{t}+K A_{t}=\Delta R_{t}$, where $C A_{t}=T B_{t}+I T_{t}$ is the current account balance.

${ }^{3}$ Our sample includes the countries classified as middle-income by the World Bank, plus Korea. It excludes major oil-producing countries, for which a large change in the price of oil could be misinterpreted as a sudden stop. The data for the financial account, the change in reserves and the income and transfers come from the IMF's International Financial Statistics. They are converted from current U.S. dollar to constant local currency units using the nominal exchange rate vis-à-vis the U.S. dollar and the local GDP deflator index. Exceptional financing and IMF loans are counted as reserves rather than capital inflows. The data for real GDP and the real GDP deflator come from the World Bank's World Development Indicators.
} 
centered around a sudden stop. ${ }^{4}$ Real output is normalized to 100 in the year prior to the sudden stop. The income and transfers from abroad are not shown because this term is small and does not vary much in a sudden stop.

We observe a large fall in the financial account in the year of the sudden stop, amounting to more than 9.5 percent of the previous year's output. This is not surprising since a large fall in the financial account is the criterion that was used to identify sudden stops. More interestingly, we see that most of the negative impact of the financial account reversal on domestic absorption is offset by a fall in reserve accumulation. Thus, domestic absorption falls by only 2.6 percent of GDP on average in the year of the sudden stop-much less than the financial account. Figure 2 also shows that the contribution of output is relatively small: real growth falls at the time of the sudden stop, but remains positive.

This evidence is consistent with the view that emerging market countries accumulate reserves in good times so as to be able to decumulate them, thereby smoothing domestic absorption, in response to sudden stops. This smoothing effect is potentially large. To illustrate, if reserves accumulation were the same in the year of the sudden stop as in the year before, domestic absorption would fall by 8.7 percent of output on average instead of 2.6 percent, other things being equal. This counterfactual experiment should be interpreted with caution because the magnitude of the capital flight could be in part endogenous to the fall in reserves. It does suggest, however, that foreign exchange reserves may well provide a sizable contribution to the smoothing of domestic absorption in response to sudden stops.

The case of Uruguay in 2002 provides a striking illustration of the role of reserves in a very severe sudden-stop episode. Following the Argentine crisis, Uruguay experienced a capital account reversal amounting to 38 percentage points of GDP. The Uruguayan government used a large amount of foreign exchange reserves (a significant part of which was made available in the context of an IMF arrangement), largely in response to the withdrawal of dollar-denominated deposits from the domestic banking system. As a result, the decline in domestic absorption, although quite substantial (15 percent of GDP), was much smaller than the shock to the capital account.

\section{THE MODEL}

Our framework is designed to capture the stylized facts on sudden stops and reserves that have just been documented. We consider a small open economy that may be hit by a sudden stop in capital inflows, and maintains a stock of reserves to smooth the impact of the sudden stop on domestic absorption. We first present the main assumptions of the model, and then derive a closed-form expression for the optimal level of reserves.

\footnotetext{
${ }^{4}$ Figure 2 is based on the events that occurred after 1980, excluding the sudden stops that occurred inside the five-year window of the previous sudden stop.
} 


\section{A. Assumptions}

We consider a small open economy in discrete time $t=0,1,2, \ldots$. There is one single good, which is consumed domestically and abroad. (Issues related to the real exchange rate will be treated in an extension of the model presented in Section V.) The economy follows a deterministic path that may be disturbed by a sudden stop, i.e., an exogenous loss of access to external credit. The only source of uncertainty in our model is the risk of a sudden stop.

The domestic economy is composed of the private sector and the government. The domestic private sector is modeled as a representative consumer who is subject to the budget constraint

$$
C_{t}=Y_{t}+L_{t}-(1+r) L_{t-1}+Z_{t}
$$

where $Y_{t}$ is domestic output, $L_{t}$ is the foreign debt of the representative consumer, and $Z_{t}$ is a transfer from the government. The interest rate $r$ is constant, and the representative consumer does not default on her external debt.

Output and private external debt both grow at the same constant rate $g$, until the sudden stop occurs. The sudden stop is modeled as a debt rollover crisis associated with a fall in output. When the sudden stop occurs, two things happen: the representative consumer is unable to roll over her external debt, and output falls by a fraction $\gamma$ below its long-run growth path. We assume that the consumer's external debt is short-term, implying that $L$ falls to zero in a sudden stop. ${ }^{5}$ After the sudden stop, private external debt remains equal to zero, and output goes back to its long-run growth path.

We assume that the sudden stop occurs with probability $\pi$ in each period. After the sudden stop, all the uncertainty is resolved, and the economy grows at rate $g<r$. The assumption that there is only one sudden stop is made for expositional simplicity. We show in Section V that our results can be extended to the case where the private sector is vulnerable to multiple sudden stops.

We respectively denote with the superscripts $b, d$, and $a$ the periods before, during, and after the sudden stop. Denoting by $\lambda$ the level of private external debt as a share of output in the pre-sudden-stop period, our assumptions so far are summarized with the following set of equations,

$$
\begin{aligned}
& Y_{t}^{b}=Y_{t}^{a}=(1+g)^{t} Y_{0}, \quad Y_{t}^{d}=(1-\gamma)(1+g)^{t} Y_{0}, \\
& L_{t}^{b}=\lambda(1+g)^{t} Y_{0}, \quad L_{t}^{d}=L_{t}^{a}=0
\end{aligned}
$$

where $\lambda$ is the level of private external debt as a share of output in the pre-sudden-stop period.

\footnotetext{
${ }^{5}$ Assuming that $L$ falls to zero is a matter of normalization. The private external debt that is rolled over does not contribute to the sudden stop and so plays no interesting role in our model.
} 
The government, unlike the private sector, can issue a long-term security that does not have to be repaid in a sudden stop. The long-term security issued by the government is a bond that yields one unit of good in every period until the sudden stop occurs. The security stops yielding any income after the sudden stop. ${ }^{6}$ The government security has a long maturity in the sense that its life expectancy, $1 / \pi$, is large if $\pi$ is small. For example, if $\pi=0.1$ (a plausible value, as we will see), the life expectancy of the security is ten years.

The pre-sudden-stop price of the security is equal to the present discounted value of the one unit of good it pays in the next period (with certainty) plus the expected market value of the security,

implying,

$$
P=\frac{1}{1+r+\delta}[1+(1-\pi) \cdot P]
$$

$$
P=\frac{1}{r+\delta+\pi}
$$

We have used the fact that the price of the long-term security is constant before the sudden stop and falls to zero when the sudden stop occurs. In addition we have assumed that the interest rate used to compute the present value of the long-term security is higher than the short-term interest rate $r$. The difference $\delta$ can be interpreted as a term premium. ${ }^{7}$

The government issues the long-term security to finance a stock of reserves,

$$
R_{t}=P N_{t}
$$

where $N_{t}$ is the number of securities issued by the government in period $t$. The reserves must be accumulated before the sudden stop because the government cannot issue any longterm security during the sudden stop.

Expression (7) can be used to substitute out $N_{t}$ and $N_{t-1}$ from the government's budget constraint,

$$
Z_{t}+R_{t}+N_{t-1}=P\left(N_{t}-N_{t-1}\right)+(1+r) R_{t-1}
$$

which gives an expression for the transfer before the sudden stop,

$$
Z_{t}^{b}=-\left(\frac{1}{P}-r\right) R_{t-1}=-(\delta+\pi) R_{t-1}
$$

\footnotetext{
${ }^{6}$ This assumption, which could be interpreted as a contingent default, simplifies the government's problem by making it independent of the past history of sudden stops.

${ }^{7}$ It does not include the default risk premium, which is already counted in $\pi$. We return to the question of how the default risk premium affects the cost of reserves in the concluding comments.
} 
The transfer is negative. The government taxes the representative consumer so as to pay for the cost of carrying the reserves, which is proportional to the term premium plus the probability of a sudden stop.

If and when the sudden stop occurs, the government transfers the reserves (net of the last payment on the long-term security) to help the representative consumer repay the external debt that is not rolled over,

$$
Z_{t}^{d}=(1-\delta-\pi) R_{t-1}
$$

We assume that $\delta+\pi<1$ to ensure that this transfer is positive. After the sudden stop the government becomes inactive: $R_{t}, N_{t}$, and $Z_{t}$ are all equal to zero.

Using equations (9) and (10) to substitute $Z_{t}$ out of equation (4) gives expressions for the level of domestic consumption respectively before, during, and after the sudden stop,

$$
\begin{aligned}
& C_{t}^{b}=Y_{t}^{b}+L_{t}^{b}-(1+r) L_{t-1}^{b}-(\delta+\pi) R_{t-1}, \\
& C_{t}^{d}=(1-\gamma) Y_{t}^{b}-(1+r) L_{t-1}^{b}+(1-\delta-\pi) R_{t-1}, \\
& C_{t}^{a}=Y_{t}^{a} .
\end{aligned}
$$

The trade-off involved in the choice of the optimal level of reserves is clear from equations (11) and (12). Increasing $R_{t-1}$ raises period $t$ consumption if there is a sudden stop at the cost of lowering it if there is no sudden stop. Accumulating reserves, in other terms, is equivalent to an insurance that transfers purchasing power from the non-sudden-stop state to the suddenstop state.

Figure 3 illustrates the dynamics of the main macroeconomic variables in a sudden stop. The figure shows the same variables as in Figure 2 to facilitate the comparison between the model and the data. The model does a good job of reproducing the stylized facts that we have documented in the previous section, in particular the fact that reserves help the government smooth domestic absorption in response to a sudden stop.

To close the model we need to specify the government's objective function. We assume that the government maximizes the welfare of the representative consumer,

$$
U_{t}=\sum_{s=0, \ldots,+\infty}(1+r)^{-s} u\left(C_{t+s}\right)
$$

where the flow utility function has a constant relative risk aversion $\sigma$,

$$
u(C)=\frac{C^{1-\sigma}-1}{1-\sigma} .
$$

The government's problem is to find the level of reserves $R_{t}$ that maximizes $U_{t}$ in each period $t$ before the sudden stop occurs. 
We conclude the presentation of our assumptions with two remarks that clarify the role of reserves management in our model. First, increasing reserves is equivalent, in our model, to lengthening the maturity of the country's consolidated external debt. Aggregating the budget constraints of the representative consumer and of the government, equations (4) and (8), gives

$$
C_{t}=Y_{t}+\left(L_{t}-P N_{t}\right)-(1+r)\left(L_{t-1}-P N_{t-1}\right)+P N_{t}-(1+r+\delta+\pi) P N_{t-1} .
$$

This equation shows that accumulating reserves is equivalent to substituting short-term debt $(L)$ by long-term debt $(P N)$ in the country's consolidated external liabilities. ${ }^{8}$ From the point of view of the aggregate budget constraint, holding reserves is equivalent to repaying short-term external debt by issuing long-term debt. Long-term debt reduces the rollover risk but entails a higher interest cost. ${ }^{9}$

Second, the model takes the behavior of the private sector as given. This raises the question of whether this behavior is optimal from the point of view of maximizing the intertemporal utility (14). In particular, why would the private sector not insure itself by building up its own stock of reserves or by preventively repaying some of its short-term debt? We will show in Section V that the assumptions that we have made about the private sector's behavior are indeed consistent with intertemporal optimization, if we assume that the government enjoys a comparative advantage relative to the private sector in issuing long-term securities.

\section{B. A Formula for the Optimal Level of Reserves}

The government chooses the level of reserves $R_{t}$ so as to maximize $U_{t}$ in each period $t$ before the sudden stop. The government's problem is fairly simple since $R_{t}$ matters only for the level of consumption in $t+1$. The optimal level of reserves in period $t$ maximizes the expected utility of period $t+1$ consumption,

$$
R_{t}=\arg \max (1-\pi) u\left(C_{t+1}^{b}\right)+\pi u\left(C_{t+1}^{d}\right)
$$

where $C_{t+1}^{b}$ and $C_{t+1}^{d}$ are given by equations (11) and (12). The first-order condition is

$$
\pi(1-\delta-\pi) u^{\prime}\left(C_{t+1}^{d}\right)=(1-\pi)(\delta+\pi) u^{\prime}\left(C_{t+1}^{b}\right)
$$

\footnotetext{
${ }^{8}$ Broner and others (2004) present a model of emerging market debt with a similar trade-off between short-term and long-term debt.

${ }^{9}$ It is irrelevant, in our model, whether the reserves are kept at the central bank or used to repay the private sector's external debt before the sudden stop. However, waiting could be optimal if some information about the optimal allocation of reserves were revealed in the sudden stop.
} 
The left-hand side is the probability of a sudden stop times the marginal utility of reserves conditional on a sudden stop. The right-hand side is the probability of no sudden stop times the marginal cost of reserves conditional on no sudden stop.

This first-order condition can be manipulated to obtain a closed-form expression for the optimal level of reserves. First, let us denote by $p_{t}$ the marginal rate of substitution between consumption in the sudden-stop state and consumption in the non-sudden-stop state,

$$
p_{t} \equiv \frac{u^{\prime}\left(C_{t}^{d}\right)}{u^{\prime}\left(C_{t}^{b}\right)}
$$

This variable can be interpreted as the relative price of a "sudden-stop dollar" in terms of a "non-sudden-stop dollar" - a measure of the liquidity premium generated by a sudden stop. The first-order condition (15) says that when reserves are set optimally, this price should be constant and equal to

$$
p \equiv \frac{1-\pi}{\pi} \frac{\delta+\pi}{1-\delta-\pi}=1+\frac{\delta}{\pi(1-\delta-\pi)}
$$

If the term premium $\delta$ is equal to zero, then $p$ is equal to 1 , implying that domestic consumption is perfectly insured against the risk of a sudden stop $\left(C_{t}^{d}=C_{t}^{b}\right)$. If the term premium is strictly positive, then $p$ is larger than 1 , implying that domestic consumption is lower in a sudden stop $\left(C_{t}^{d}<C_{t}^{b}\right)$.

Simple manipulations of the first-order condition (reported in the Appendix) show that the optimal level of reserves in normal times is a fixed fraction of the level of output,

$$
R_{t}=\rho Y_{t+1}^{b}
$$

where the optimal reserves-to-output ratio $\rho$ is given by

$$
\rho=\lambda+\gamma-\frac{p^{1 / \sigma}-1}{1+\left(p^{1 / \sigma}-1\right)(1-\delta-\pi)}\left(1-\frac{r-g}{1+g} \lambda-(\delta+\pi)(\lambda+\gamma)\right) .
$$

Equation (16) is the formula for the optimal level of reserves in our model. A good approximation to the exact formula, in the range of parameter values that we will consider in the calibration, can be obtained by setting $\delta+\pi=r-g=0$ in the last term of equation (16),

$$
\rho \approx \lambda+\gamma-\left(1-p^{-1 / \sigma}\right)
$$

The approximate formula shows that the optimal level of reserves is increasing one for one with the amount of short-term debt and the output cost of a sudden stop. As noted earlier, if 
the term premium $\delta$ is equal to zero, then $p$ is equal to 1 , and reserves should be set to the level that perfectly smoothes the impact of the sudden stop on domestic consumption, $\rho=\lambda+\gamma$. The optimal level of reserves falls with an increase in $p$, which in turn could be caused by a decrease in the probability of a sudden stop, $\pi$, or an increase in the term premium, $\delta .{ }^{10}$ An increase in the risk aversion parameter $\sigma$ decreases $p^{1 / \sigma}$ and raises the optimal level of reserves.

How does our formula relate to the Greenspan-Guidotti rule? This rule says that the ratio of the reserves to short-term debt should be equal to 1, that is,

$$
\rho=\lambda
$$

This rule perfectly smoothes consumption in a sudden stop if there is no output cost. As shown by equation (17), the optimal level of reserves could be lower or higher than the Greenspan-Guidotti rule. It could be higher because reserves smooth the impact of the output loss (this is captured by the term $\gamma$ on the right-hand side of equation (17)). It could be lower because of the cost of holding reserves (this is captured by the last term in equation (17)).

\section{Applications}

We calibrate the model by using the same sample of sudden stops as in Section II. We first construct a benchmark calibration by reference to the average sudden stop in our sample and present some sensitivity analysis (subsection A). We then present regional estimates of the optimal of reserves and compare them with the data (subsection B).

\section{A. Benchmark Calibration and Sensitivity Analysis}

The behavior of the model economy is determined by seven parameters: the probability of a sudden stop $\pi$, the output loss ratio $\gamma$, the ratio of short-term debt to GDP $\lambda$, the return on reserves $r$, the term premium $\delta$, and the risk-aversion parameter $\sigma$. Our benchmark calibration is given in Table 2 .

Three parameters $(\pi, \lambda$, and $\gamma$ ) have been calibrated by using the same sample of sudden stops as in Section II. The unconditional probability of a sudden stop is 10.2 percent per year, which is rounded to $\pi=0.1$ in the calibration. Parameter $\lambda$ was calibrated as the average level of $\left(k_{t-1}-k_{t}\right)$ over our sample of sudden stops, which is close to 11 percent. Looking at the ratio of short-term external debt to GDP would give similar values. This ratio is equal to 8.2 percent on average in our sample according to the World Bank's Global Development

\footnotetext{
${ }^{10}$ The total derivative of $\rho$ with respect to $\delta$ or $\pi$ has an ambiguous sign in the exact formula. For the range of parameter values that we consider in the calibration, however, $\rho$ is decreasing with $\delta$ and increasing with $\pi$.
} 
Finance (GDF) data set, and to 11.7 percent according to the Bank of International Settlements (BIS) database. ${ }^{11}$

We calibrated the output cost of a sudden stop by looking at the average difference between the GDP growth rate in normal times and the growth rate in sudden stops. We find that the growth rate falls by 4.5 percent on average relative to normal times in a sudden stop and by 2.2 percent in the following year. ${ }^{12}$ Thus we set $\gamma$ to 6.5 percent in our benchmark calibration. This is consistent with the output cost of currency crises as estimated, for example, by Rancière and others (2003).

The risk-free short-term dollar interest rate $r$ is set at 5 percent. The value for the term premium, $\delta=1.5$ percent, is the average differential between the yield on 10-year U.S. Treasury bonds and the federal fund rate during 1987-2005. The growth rate $g$ is set at 3.3 percent, the average real GDP growth rate in our sample of middle-income countries during 1975-2002 (excluding sudden-stop years). The benchmark risk aversion and its range of variation are standard in the growth and real business cycle literature.

Our benchmark calibration implies an optimal level of reserves of 10.1 percent of GDP, or 92 percent of the short-term external debt. This is close to the ratio of reserves to GDP observed in the data on average during 1975-2003 (9.4 percent), but significantly lower than the level observed in the most recent period, especially in Asia. It would be interesting to know what changes in the parameters would be required to increase the optimal level of reserves. The remainder of this section explores the sensitivity of our results to parameter values.

Figure 4 shows how the optimal level of reserves depends on the size of the sudden stop, the probability of sudden stop, the term premium, and the degree of risk-aversion. In each case, we contrast the level of reserves computed using our model with the one implied by the Greenspan-Guidotti rule. Several interesting results emerge. First, the Greenspan-Guidotti rule provides a good approximation to how the optimal level of reserves varies with the size of sudden stops. The optimal ratio of reserves to short-term debt remains in the 90 to 100 percent range if the size of the sudden stop exceeds 10 percent of GDP. This is not true, however, for small sudden stops: the optimal level of reserves is equal to zero if short-term debt amounts to less than 2.5 percent of GDP. This is because the marginal benefit of smoothing domestic absorption varies in proportion with the size of the sudden stop, whereas the marginal cost of holding reserves is constant.

\footnotetext{
${ }^{11}$ One source of discrepancy is that the definition of short-term debt is based on original maturity in the GDF data but on residual maturity in the BIS data. The two data sets also differ in their country coverage.

12 The output loss is slightly larger than the numbers reported in our event study (see Figure 2) because the sample of sudden stops is slightly different: it includes all the sudden stops since 1975, without excluding those that occur within the five-year window centered on the previous sudden stop.
} 
Second, the optimal level of reserves is quite sensitive to the probability of a sudden stop, the term premium, and the risk aversion parameter. This offers an interesting contrast with the Greenspan-Guidotti rule, which does not depend at all on these parameters. Doubling the probability of a sudden stop from 5 percent to 10 percent more than doubles the optimal level of reserves, from 4.6 percent to 10.1 percent of GDP. Increasing the term premium by its historical standard deviation (from 1.5 percent to 3 percent) reduces the optimal reserve-toGDP ratio from 10.2 percent to 3.8 percent. Risk aversion also has a first-order impact on the optimal level of reserves. A shift in risk-aversion from 1 to 4 increases the optimal level of reserves from 3 percent to 14 percent of GDP. However, because the optimal level of reserves is a strongly concave function of risk aversion, an increase in risk aversion from 6 to 8 has a much milder impact.

\section{B. Regional Estimates}

Next we produce estimates of the optimal level of reserves by taking into account crossregional differences in the risk of a sudden stop. We first estimate an empirical equation for the probability of a sudden stop, $\pi$, based on a set of country-specific fundamentals. We then use the formulas derived in Section III to compute the optimal level of reserves for specific countries and regions.

\section{Estimating the Probability of Sudden Stop}

The probability of a sudden stop is estimated as a function of a country's economic fundamentals by running a probit estimation of the probability of sudden stops in our sample of 34 middle income countries during 1975-2003. Our preferred specification is reported in Table 3. The explanatory variables have been selected using a general-to-specific approach, starting from a set of 24 potential regressors. ${ }^{13}$ We also report the impact of a fixed exchange rate regime dummy (although this variable is not statistically significant in our preferred specification) because the role of the exchange rate regime is of special interest. All explanatory variables are averages of the first and second lags, and are thus predetermined with respect to the sudden stop. The results are robust to the inclusion of time effects and fixed effects.

We find that the probability of a sudden stop decreases with the pre-crisis growth performance, and increases with the currency's real appreciation, the ratio of public debt to GDP, the country's openness to financial flows (measured by the absolute value of gross inflows as a share of GDP), and the ratio of foreign liabilities to money in the banking sector $^{14}$ (regression 3.1). The last two determinants suggest that the vulnerability to sudden stops rises with the degree of international financial integration. Interestingly, we found that

\footnotetext{
${ }^{13}$ The regressors are listed in Table 4.

${ }^{14}$ The ratio of foreign liabilities of the financial sector to money in the banking sector is a reasonable proxy for, though not a direct measure of, mismatch in the currency denomination of assets and liabilities in countries' balance sheets.
} 
trade openness did not significantly affect the probability of a sudden stop when financial openness was included as an explanatory variable. A fixed exchange rate regime is associated with a higher probability of a sudden stop, though only if financial openness and exchange rate overvaluation are omitted from the regression (regression 3.2). Our estimation remain robust when different combination of time and fixed effects are introduced in the specification (regressions 3.3, 3.4, 3.5).

We were less successful in our attempts to estimate an empirical equation for the size of sudden stops, $\lambda$. Although this variable exhibits a lot of variation across countries and over time, a robust relationship is more difficult to identify in the data-even, somewhat surprisingly, with the country's financial openness. Therefore, we take the average size of the sudden stop (10.8 percent of GDP) to compute our estimates.

\section{Benchmark Calibration and Sensitivity Analysis}

Before turning to our estimates, it may be useful to assess the impact of a change in fundamentals on the optimal level of reserves in our model economy. Our benchmark economy is now calibrated as an "average" middle-income economy whose fundamentals are initially set at their sample mean. The probit model (regression 3.1) predicts a suddenstop probability of 7.9 percent for this average economy, ${ }^{15}$ implying an optimal level of the ratio of reserves to GDP of 8.6 percent. We analyze the effect of a change in each fundamental on the predicted probability of a sudden stop and consequently on its optimal reserves-to-GDP ratio.

As shown in Table 5, plausible changes in fundamentals have a substantial impact on the optimal level of reserves. A 20 percent real appreciation increases the estimated annual probability of a sudden stop by approximately 4.3 percentage points, and generates an increase in the optimal level of reserves of 2.7 percentage points of GDP. A rise in the ratio of public debt to GDP from 40 percent to 60 percent implies an increase in the optimal reserve ratio by 1.7 percentage points of GDP. A rapid buildup of the ratio of foreign liabilities to money, calibrated on the experience of Thailand between 1990 (45 percent) and 1997 (262 percent), raises the optimal level of reserves by 3.7 percentage points of GDP. A one standard deviation increase in the degree of financial openness leads optimal reserves to increase by 3.2 percentage points of GDP. Finally, a change from a floating to a fixed exchange rate regime induces an increase in the optimal level of reserves of 3.4 percentage points of GDP.

\section{Regional Trends}

We now look at the model's ability to explain recent trends in reserves accumulation at the regional level. The optimal level of reserves - based on the model - is computed for each country and year for the 34 middle income countries in our sample. The probability of a sudden stop is computed on the basis of the probit estimates. The size of the sudden stop is

\footnotetext{
${ }^{15}$ This probability is slightly smaller than the frequency of sudden stops in the sample because of the convexity in the probit function.
} 
set to its realized mean value in each region and each decade. The only unobservable parameter, risk aversion, is now set equal to 6-a value selected to match the actual mean level of reserves to GDP in Asia in the middle of the sample period (1991). The results are then aggregated to obtain regional averages for Latin American and Asian emerging markets. Using this approach, it is possible to compare changes over time in the optimal level of reserves, actual reserves, and the three-months-of-imports and Greenspan-Guidotti rules of thumb. The results are presented in Figure 5.

For the group of Asian emerging markets, the model suggests that reserves should have declined somewhat between the early and the late 1980s: in the aftermath of the debt crisis of the early 1980s, a slowdown in financial flows to emerging markets contributed to reducing the probability of sudden stops. Beginning in the early 1990s, the model implies a rapid increase in optimal reserves, owing to rising international financial integration. The slight decline in optimal reserves following the Asian crises is primarily accounted for by the reduction in public debt and financial flows. Although the model is intended to be normative, it is interesting to note that it outperforms the rules of thumb in predicting the actual level of reserves for most of the period under consideration. In particular, the upward trend in reserves in Asia during the decade prior to the Asian crisis (1985-96) is matched more closely by the model than by the alternative rules.

For the Asian countries following 1997-98, however, the model suggests that the buildup in reserves has been excessive - a finding consistent with previous analyses (Aizenman and Marion, 2003; IMF, 2003). A possible caveat is that the Asian crisis may have led to an upward revision of the size of the sudden stop or of the output loss resulting from sudden stops, though the revision would need to be very large for actual accumulation to be consistent with the increase in optimal reserves implied by the model. For example, in order for the model to explain the increase in the average level of reserves held by emerging Asian countries between 1997 and 2003, the expected size of either the sudden stop or the output cost would have had to more than double relative to its average level observed in the $1990 \mathrm{~s} .{ }^{16}$

In Latin America, the model suggests relatively high optimal reserves (far above actual reserves) in the 1980s, a turbulent period characterized by high likelihood of crises for the region; lower levels of optimal reserves in the early 1990s, partly on account of improved fundamentals (public debt and economic growth); and rising optimal reserves during the past decade, in line with heightened international financial integration. The close match between the model and the data in 1991-2003 is notable, considering that no individual-year level of reserves for Latin America has been used in the calibration. The model might be interpreted to suggest that the current level of reserves is, on average, adequate in Latin America. However, it is important to note that reserve coverage is estimated to be insufficient in some relatively large individual countries.

\footnotetext{
${ }^{16}$ By contrast, increasing the risk-aversion parameter from 6 to 10 (the maximum value considered in existing studies on growth and business cycles) would lead the warranted level of reserves to increase by less than 3 percentage points of GDP, much less than needed to explain the post-crisis buildup in emerging Asia's reserves.
} 


\section{EXTENSIONS}

Our framework may be extended and generalized so as to capture other determinants of the optimal level of reserves. This section presents four such extensions. The first one assumes that the probability of a sudden stop is decreasing with the level of reserves. The second extension relaxes the assumption that there is one single good and analyzes the impact of having a real exchange rate depreciation at the same time as the sudden stop. The third one probes the robustness of our results to an optimizing private sector. The last extension shows how the analysis can be extended to a model with multiple sudden stops.

\section{A. Crisis Prevention}

Our model focuses on the benefits of reserves in terms of crisis mitigation. An additional benefit of reserves might be to instill confidence in the economy and thus reduce the probability of a sudden stop (Garcia and Soto, 2004). ${ }^{17}$ This can be captured in reduced form by assuming that the probability of crisis is a decreasing function of the pre-crisis level of reserves,

$$
\pi_{t}=\Pi\left(\rho_{t}\right), \quad \Pi^{\prime}<0
$$

The problem is then the same as before except that one must take into account the dependence of the probability of a sudden stop to the level of reserves.

The specification of function $\Pi(\cdot)$ could be based on more micro-founded models of crisis. In the currency-crisis model of Morris and Shin (1998), for example, the probability of a crisis is a decreasing function of the level of reserves. One could also use models in which crises are self-fulfilling and triggered by an extrinsic "sunspot" variable. A typical property of models with multiple equilibria is that the crisis equilibrium is removed if and only if the reserves are sufficient to repay all the short-term creditors (see, e.g., Zettelmeyer, 2000). This might provide a theoretical basis for the Greenspan-Guidotti rule.

Let us assume that the sudden stop can be triggered by a sunspot variable whenever shortterm debt is not fully covered by reserves; that is,

$$
\begin{aligned}
& \Pi(\rho)=\pi^{s} \text { for } \rho<\lambda, \\
& \Pi(\rho)=0 \text { for } \rho \geq \lambda,
\end{aligned}
$$

where $\pi^{s}$ denotes the exogenous probability of a sunspot event.

\footnotetext{
${ }^{17}$ Bussière and Mulder's (1999) findings suggest that the Greenspan-Guidotti rule is an appropriate benchmark to avoid contagion-related crises in emerging market countries with good macroeconomic fundamentals. Rodrik and Velasco (2000) estimate that a country that abides by the Greenspan-Guidotti rule reduces the annual probability of experiencing a sharp reversal in capital flows by 10 percentage points on average. Edwards (2004) also finds that the probability of a capital account reversal decreases with the level of international reserves.
} 
The government will never set $\rho>\lambda$ since holding reserves in excess of $\lambda$ yields no benefit once the probability of sudden stop is equal to zero. The government now chooses between two options: (1) setting $\rho=\lambda$ (the Greenspan-Guidotti rule), or (2) setting $\rho$ to the optimal level conditional on $\pi=\pi^{s}$. The optimal policy is derived by comparing the expected discounted flow of utility of an economy exposed to the risk of a sudden stop to the expected discounted flow of utility of an economy fully covered against this risk.

One can show that the Greenspan-Guidotti rule is optimal for the benchmark calibration of Table 2 (with $\pi^{s}$ equal to 11 percent). ${ }^{18}$ This result is intuitive. The optimal level of reserves, at 92 percent of short-term debt, was already close to the Greenspan-Guidotti rule when the probability of a sudden stop was exogenous. Making the domestic economy completely immune to the risk of a sudden stop is worth the cost of increasing reserves from 92 percent to 100 percent of short-term debt. Thus, it is not difficult for a plausible calibration of the model with endogenous probability of a sudden stop to rationalize the Greenspan-Guidotti rule.

In general, making the probability of a sudden stop endogenous to the level of reserves could increase or decrease the optimal level of reserves. Although we have presented an example where the optimal level of reserves is increased, it is not difficult to obtain the opposite result. If the optimal level of reserves is larger than short-term debt conditional on an exogenous probability of a sudden stop, then applying the Greenspan-Guidotti rule decreases the level of reserves.

\section{B. Real Exchange Rate Depreciation}

We now consider valuation effects caused by a real exchange rate depreciation at the time of the sudden stop. Let us assume that the country's external liabilities and reserves are denominated in foreign currency. Then the budget constraint of the representative consumer, equation (4), is replaced by

$$
C_{t}=Y_{t}+Q_{t}\left(L_{t}-(1+r) L_{t-1}+Z_{t}\right)
$$

where $Q_{t}$ is the real exchange rate at time $t$. We assume that the real exchange rate is constant (and normalized to 1) before the sudden stop, and depreciates by $\Delta Q$ at the time of the sudden stop,

$$
Q_{t}^{b}=Q_{t}^{a}=1, Q_{t}^{d}=1+\Delta Q
$$

The same amount of reserves provides more insurance than in the model without depreciation, because the value of reserves in terms of domestic consumption increases at the time of the sudden stop. This has an ambiguous effect on the optimal level of reserves. On the one hand, the cost of a given level of insurance falls, which increases the demand for insurance. On the other hand, the same level of insurance can be achieved with fewer reserves.

${ }^{18}$ The details are available upon request to the authors. 
The formula for the optimal level of reserves is derived in the Appendix. It turns out that the optimal level of reserves is not significantly affected by the real depreciation for our benchmark calibration. For example, assuming a real depreciation of 10 percent (which is close to the average level observed in our sample of sudden stops) barely changes the optimal level of reserves relative to the benchmark model-it increases from 10.1 percent to 10.2 percent of GDP. Thus, the possibility of a real depreciation does not seem to lead to a substantial revision of the formula obtained in the one-good model.

\section{Endogenizing the Behavior of the Private Sector}

Our model takes the behavior of the representative consumer as exogenous. We now show that this behavior is consistent with intertemporal optimization subject to an external credit constraint. Let us assume that the representative consumer cannot borrow more than a share $\lambda$ of domestic output before the sudden stop,

$$
L_{t}^{b} \leq \lambda Y_{t}^{b}
$$

In the benchmark model we have assumed that this borrowing constraint was binding. The question is whether it is indeed binding if the representative consumer maximizes her intertemporal utility (14). It could be binding because consumption grows at rate $g$, whereas the unconstrained consumer would like to maintain a constant consumption path. However, this consideration has to be weighed against the fact that the consumer might want to reduce her short-term debt (or equivalently, accumulate private reserves) so as to mitigate the impact of a sudden stop on her consumption. On balance, the constraint is binding if the marginal utility of consumption today is higher than the expected marginal utility of consumption tomorrow,

$$
u^{\prime}\left(C_{t}^{b}\right)>(1-\pi) u^{\prime}\left(C_{t+1}^{b}\right)+\pi u^{\prime}\left(C_{t+1}^{d}\right)
$$

Using equation (15), this condition can be rewritten,

$$
u^{\prime}\left(C_{t}^{b}\right)>\frac{1-\pi}{1-\delta-\pi} u^{\prime}\left(C_{t+1}^{b}\right)
$$

and using the fact that consumption grows at rate $g$ before the sudden stop,

$$
(1+g)^{\sigma}>1+\frac{\delta}{1-\delta-\pi}
$$

One can check that this condition is satisfied for our benchmark calibration, implying that the behavior that we have assumed for the private sector is consistent with intertemporal optimization. It is interesting that the private incentives to accumulate reserves are decreased by government reserves. In the absence of government reserves, condition (18) is more likely to be violated, in which case the representative consumer would find it optimal to hold some private reserves or repay some of her short-term debt. In a sense the accumulation of reserves 
by the government encourages the private sector to issue short-term debt. This is not a sign of moral hazard, however: restricting the private sector's issuance of short-term debt would be welfare-decreasing in our model.

\section{Multiple Sudden Stops}

We outline a generalization of the model in which sudden-stop episodes can last more than one period and there can be more than one sudden stop. Let us assume that it takes a certain number of periods $\theta$ for output and external credit to go back to their normal levels after a sudden stop. Thus, a full sudden-stop episode that starts in period $t$ lasts until period $t+\theta$. During the sudden-stop episode we have

$$
\begin{gathered}
Y_{t+s}=\left(1-\gamma_{s}\right) Y_{t+s}^{b}, \\
L_{t+s}=\lambda_{s} Y_{t+s}^{b},
\end{gathered}
$$

for $s=0, \ldots, \theta$, where $Y_{t}^{b}$ is now interpreted as potential output. The profile of a sudden-stop episode is determined by the exogenous parameters, $\left(\gamma_{s}, \lambda_{s}\right)_{s=0, \ldots, \theta}$. The model presented in Section III corresponds to the special case where $\theta=+\infty, \gamma_{0}>0, \gamma_{s}=0$ for $s>0$, and $\lambda_{s}=0$ for all $s$.

Let us assume that the profile of the sudden-stop is such that it is optimal for the government to use all the reserves in the first period of the sudden-stop episode. Then the government's problem is exactly the same as in the model of Section III. In normal times the government does not inherit any liability from the previous sudden-stop episode. It accumulates the optimal level of reserves to smooth domestic consumption in the first period of the next sudden-stop episode. Our formula for the optimal level of reserves, thus, remains valid.

\section{Concluding Comments}

This paper derives a simple formula for the optimal level of international reserves, based on the assumption that the main benefit of reserves is to smooth domestic absorption against the disruption induced by sudden stops in capital flows. Three directions would seem especially interesting for extending our framework in future work.

First, we would like to better understand the role of default risk as a determinant of the cost of holding reserves. The default risk premium is generally included in the interest rate differentials that are used to compute the opportunity cost of holding reserves (Rodrik, 2006). It is not clear, however, that the default risk premium - a compensation for the risk that the debt will not be repaid - should be counted in the same way as the term premium. A default or suspension of debt service may be viewed as a (disruptive) way for the debtor country to smooth domestic absorption. A rigorous analysis of the implications for optimal reserves requires further research.

Second, the preventive role of reserves in reducing the probability and severity of sudden stops is worth further exploration. Extending our framework to make the probability of 
sudden stop- or other variables ${ }^{19}$ - endogenous to the level of reserves raises no fundamental conceptual problem. The difficulty lies more, in our view, in the empirical estimation of the two-way causal relationship between the level of reserves and the other variables, which will be necessary to calibrate the extended model.

Finally, it would be interesting to look at issues related to the collective management of reserves. What would be the benefits of reserve pooling between emerging market countries? What are the consequences, for reserve accumulation and domestic welfare, of an institution such as the IMF that relaxes the external credit constraint of emerging market countries in a crisis? These questions could be analyzed using a multicountry extension of the framework presented in this paper.

\footnotetext{
${ }^{19}$ For example, a larger stock of reserves could lower the interest rate on external borrowing (Hauner, 2005), or it could lower the output cost of crises.
} 
Table 1. Countries and Years of Sudden Stops

\begin{tabular}{ll}
\hline Country & Dates of Sudden Stops \\
\hline Argentina & $1989 ; 2001 ; 2002$ \\
Bolivia & $1980 ; 1982 ; 1983 ; 1994$ \\
Botswana & $1977 ; 1987 ; 1991 ; 1993$ \\
Brazil & 1983 \\
Bulgaria & $1990 ; 1994 ; 1996 ; 1998$ \\
Chile & $1982 ; 1983 ; 1985 ; 1991 ; 1995 ; 1998$ \\
China, P.R.: Mainland & \\
Colombia & \\
Costa Rica & \\
Czech Republic & $1996 ; 2003$ \\
Dominican Republic & $1981 ; 1993 ; 2003$ \\
Ecuador & $1983 ; 1986 ; 1988 ; 1992 ; 1999 ; 2000$ \\
Egypt & $1990 ; 1993$ \\
El Salvador & 1979 \\
Guatemala & \\
Honduras & $1998 ; 2000$ \\
Hungary & $1994 ; 1996$ \\
Jamaica & $1983 ; 1985 ; 1986 ; 1988 ; 2002 ; 2003$ \\
Jordan & $1976 ; 1979 ; 1980 ; 1984 ; 1989 ; 1992 ;$ \\
& $1993 ; 1998 ; 2001$ \\
Korea & $1986 ; 1997$ \\
Malaysia & $1984 ; 1987 ; 1994 ; 1999$ \\
Mexico & $1982 ; 1995$ \\
Morocco & $1978 ; 1995$ \\
Paraguay & $1988 ; 1989 ; 1995 ; 2002$ \\
Peru & $1983 ; 1984 ; 1998$ \\
Philippines & $1983 ; 1997$ \\
Poland & $1988 ; 1990$ \\
Romania & 1988 \\
South Africa & 1985 \\
Sri Lanka & \\
Thailand & $1982 ; 1997 ; 1998$ \\
Tunisia & $1994 ; 2001$ \\
Turkey & $1982 ; 2002$ \\
Uruguay & \\
& \\
& \\
& \\
&
\end{tabular}


Table 2. Calibration Parameters

\begin{tabular}{lllc}
\hline \multicolumn{1}{c}{ Parameters } & \multicolumn{2}{c}{ Baseline } & Range of Variation \\
\hline & $\lambda=0.11$ & {$[0,0.3]$} \\
Size of sudden stop & $\pi=0.10$ & {$[0,0.25]$} \\
Probability of a sudden stop & $\gamma=0.065$ & {$[0,0.2]$} \\
Output loss & $\mathrm{g}=$ & 0.033 & \\
Potential output growth & $\delta=$ & 0.015 & {$[0.0025,0.05]$} \\
Term premium & $\mathrm{r}=0.05$ & {$[1,10]$} \\
Risk free rate & $\sigma=2$ & \\
Risk aversion & $\sigma$ &
\end{tabular}

Source: Author's calculations using data from IMF, International Financial Statistics, and the U.S. Federal Reserve Board.

Table 3. Probit Estimation of the Probability of a Sudden Stop

\begin{tabular}{llllll}
\hline & $(3.1)$ & $(3.2)$ & $(3.3)$ & $(3.4)$ & $(3.5)$ \\
\hline Real effective exchange rate: & 1.515 & & 1.521 & 1.851 & 1.783 \\
Deviation from HP-trend & $(3.12)^{* * *}$ & & $(2.93)^{* * *}$ & $(3.43)^{* * *}$ & $(3.05)^{* * *}$ \\
GDP growth & -1.254 & & -1.563 & -1.42 & -1.87 \\
& $(1.62)^{*}$ & & $(1.69)^{*}$ & $(1.72)^{*}$ & $(1.84)^{*}$ \\
Public debt/GDP & 0.807 & 0.78 & 0.723 & 1.015 & 0.848 \\
& $(3.33)^{* * *}$ & $(3.46)^{* * *}$ & $(2.64)^{* * *}$ & $(2.41)^{* *}$ & $(1.58)$ \\
Ratio of foreign liabilities to & 0.225 & 0.1968 & 0.215 & 0.219 & 0.197 \\
$\quad$ money in the banking sector & $(3.03)^{* * *}$ & $(2.68)^{* * *}$ & $(2.75)^{* * *}$ & $(2.22)^{* *}$ & $(1.89)^{*}$ \\
Financial openness as & 9.106 & & 10.036 & 9.822 & 11.15 \\
$\quad(\mid$ Gross Inflows|)/GDP & $(5.68)^{* * *}$ & & $(5.53)^{* * *}$ & $(4.92)^{* * *}$ & $(4.87)^{* * *}$ \\
Dummy for fixed exchange & & 0.29 & & & \\
$\quad$ rate regime & & $(1.77)^{*}$ & & & \\
Constant & -2.306 & -1.8 & -2.409 & & \\
& $(12.57)^{* * *}$ & $(12.92)^{* * *}$ & $(5.25)^{* * *}$ & & \\
\hline & & & & & \\
Observations & 707 & 690 & 707 & 537 & 537 \\
Pseudo R & 0.14 & 0.06 & 0.17 & & \\
Time effects & No & No & Yes & No & Yes \\
Fixed effects & No & No & No & Yes & Yes \\
\hline Sources: IMF, Inter & & & & & \\
\hline
\end{tabular}

Sources: IMF, International Financial Statistics; World Bank, Global Development Finance; and authors' calculations.

Notes: *significant at 10\%; **significant at 5\%;***significant at $1 \%$. Absolute value of $z$-statistics in parentheses. All explanatory variables are taken as average of first and second lags. The dummy for the fixed exchange rate regime comes from the Reinhart and Rogoff (2004) classification. 
Table 4: Variables Used in Regression Analysis

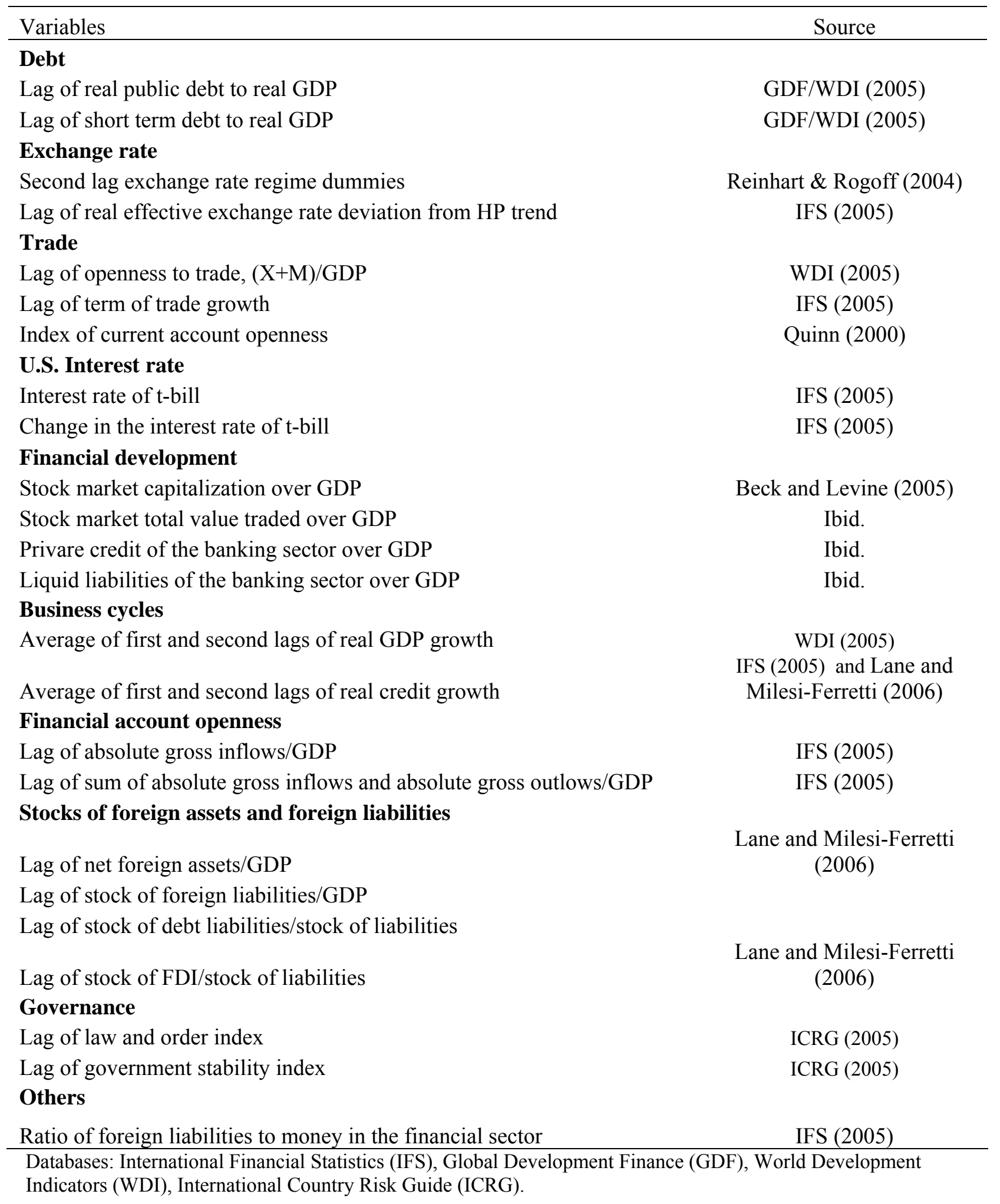


Table 5. Changes in Fundamentals and Optimal Reserves (In percentage points unless otherwise noted)

\begin{tabular}{|c|c|c|c|c|}
\hline $\begin{array}{l}\text { Fundamentals } \\
\text { (in percent unless } \\
\text { otherwise noted) }\end{array}$ & $\begin{array}{l}\text { Sample } \\
\text { Mean }\end{array}$ & $\begin{array}{l}\text { Parameter Change } \\
\text { (in percent) }\end{array}$ & $\begin{array}{c}\text { Estimated } \\
\text { Change in } \\
\text { Sudden- } \\
\text { Stop } \\
\text { Probability }\end{array}$ & $\begin{array}{c}\text { Change in } \\
\text { Optimal } \\
\text { Ratio of } \\
\text { Reserves } \\
\text { to GDP } \\
\end{array}$ \\
\hline $\begin{array}{l}\text { Exchange rate } \\
\text { overvaluation }\end{array}$ & 0.0 & $0 \rightarrow 20$ & 4.3 & 2.7 \\
\hline Public debt /GDP & 40.0 & $\begin{array}{c}40 \rightarrow 60 \\
45 \text { (Thailand, 1990) }\end{array}$ & 2.2 & 1.7 \\
\hline $\begin{array}{l}\text { Foreign liabilities / } \\
\text { money }\end{array}$ & 46.0 & $\begin{array}{c}\rightarrow 262 \text { (Thailand, } \\
\text { 1997) }\end{array}$ & 7.0 & 3.7 \\
\hline $\begin{array}{l}\text { Financial openness } \\
\text { defined as (|gross } \\
\text { inflows|) /GDP }\end{array}$ & 5.5 & $5.5 \rightarrow 10.4$ & 5.4 & 3.2 \\
\hline $\begin{array}{l}\text { Exchange rate } \\
\text { regime }\end{array}$ & & Floating $\rightarrow$ Fixed & 5.3 & 3.4 \\
\hline
\end{tabular}

Note: The initial optimal level of reserves is equivalent to 8.2 percent of GDP (about 3 months of imports, or 105 percent of short-term debt). The results are based on regression (3.1) in Table 3-except for the exchange rate regime, which is based on regression (3.2). All fundamentals are averages of the first and second lags. 


\section{Figure 1. International Reserves as a Share of GDP} (In percentage points)

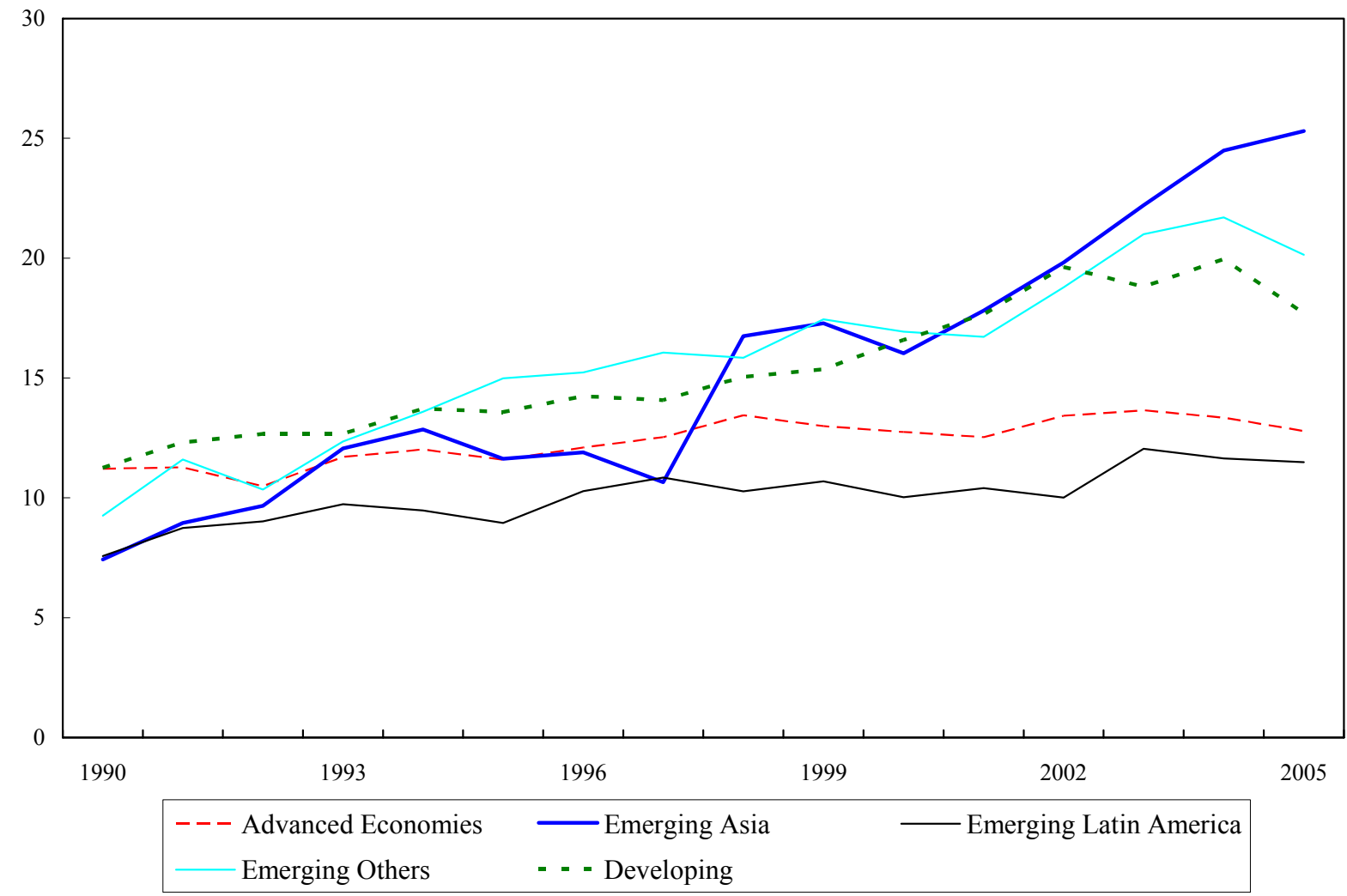

Sources: IMF, International Financial Statistics and World Economic Outlook (WEO) and World Bank, World Development Indicators.

Note: Data for 2005 refer to the end of the second quarter for the stocks of reserves, and to WEO projections for GDP. "Emerging Others" includes emerging economies in Eastern Europe, the Middle East and Africa. For each country group, the data refer to unweighted cross-country averages. 
Figure 2. Domestic Absorption and International Reserves in Sudden Stops, 1980-2003

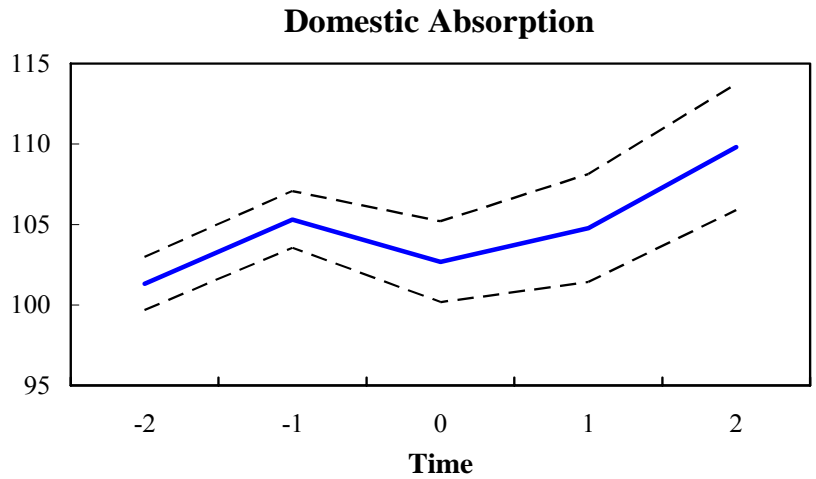

Financial Account

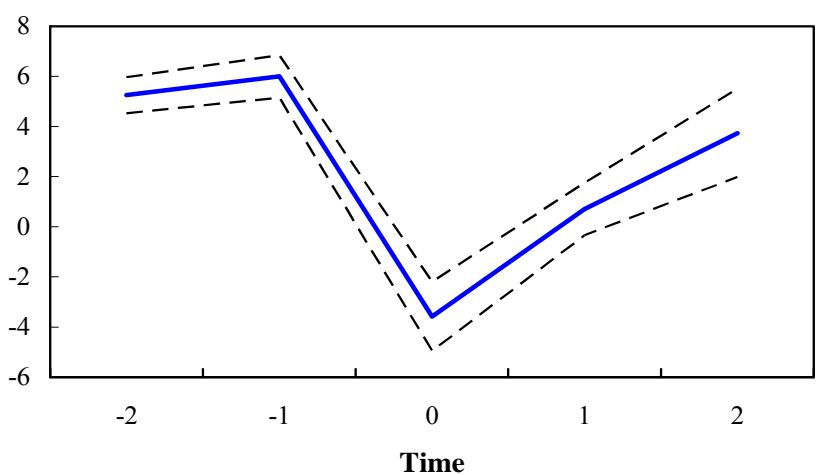

Domestic Output

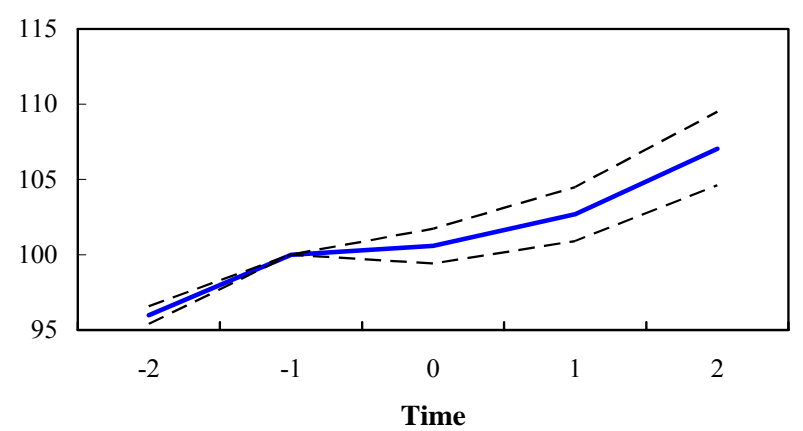

Change in Reserves

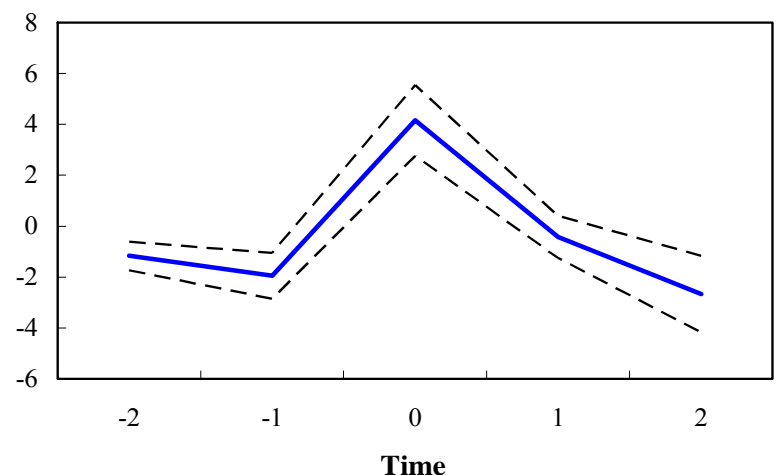

Mean - - - One standard error band

Source: Authors' computations based on IMF, International Financial Statistics and World Bank, World Development Indicators.

Note: The five-year event window is centered around a sudden stop occurring at time zero. The list of countries and sudden-stop years is given in Table 1 . The events that occurred before 1980 or inside the five-year window of the previous sudden stop were excluded. All variables are expressed in percentage points of GDP in the year before the sudden stop. 
Figure 3. Domestic Absorption and International Reserves in Sudden Stops in the Model

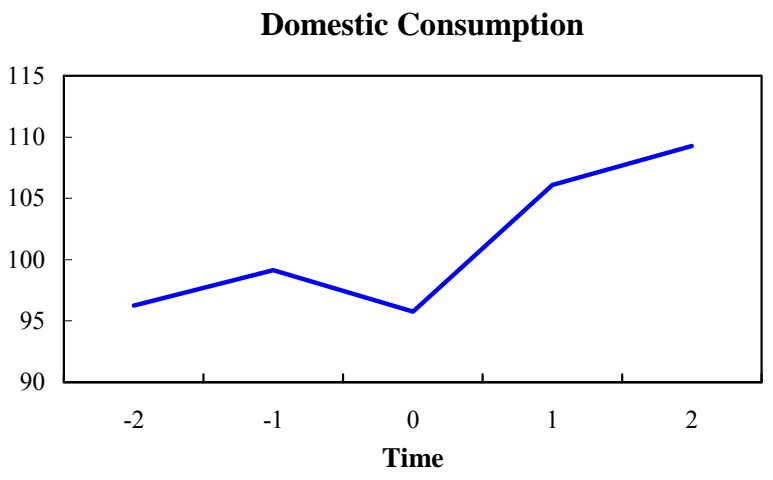

Financial Account

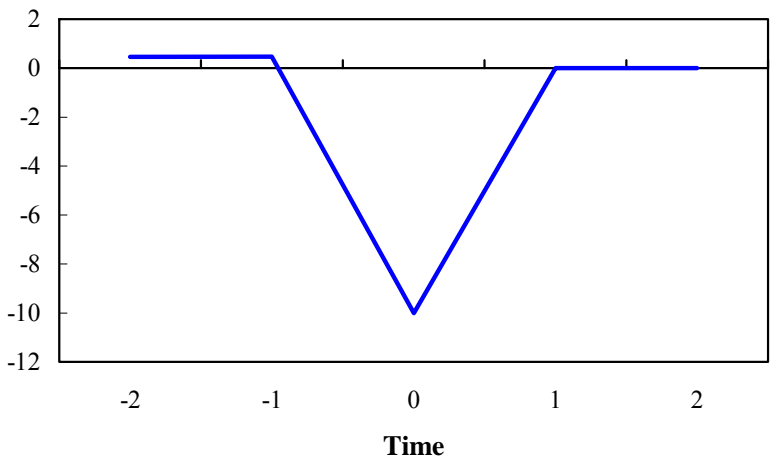

Domestic Output

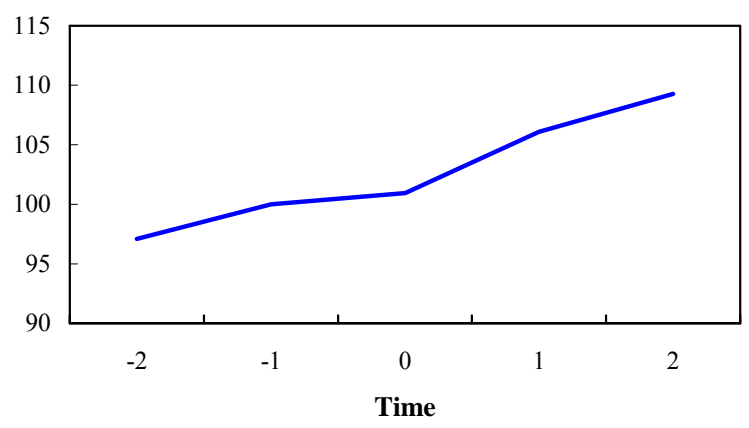

Change in Reserves

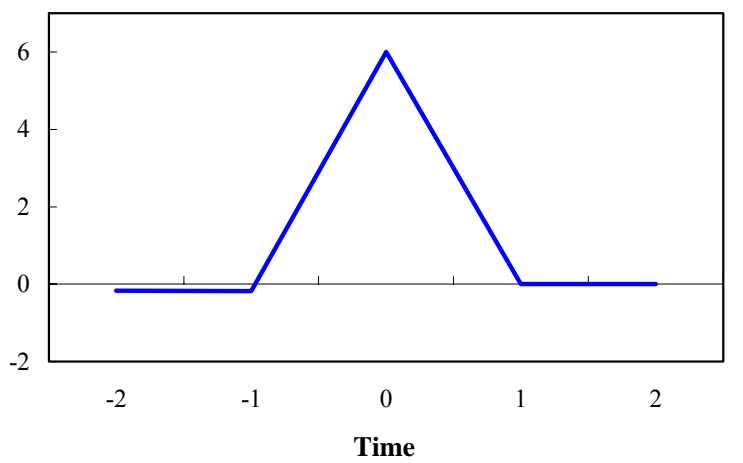

Source: Authors' computations. Reserves are assumed to amount to 6 percent of GDP before the sudden stop. The other parameters were set to the following values: $g=0.03, \lambda=0.1, \gamma=0.02, \pi=0.1, r=0.05, \delta=0.015$. 
Figure 4. The Optimal Level of Reserve: Sensitivity Analysis
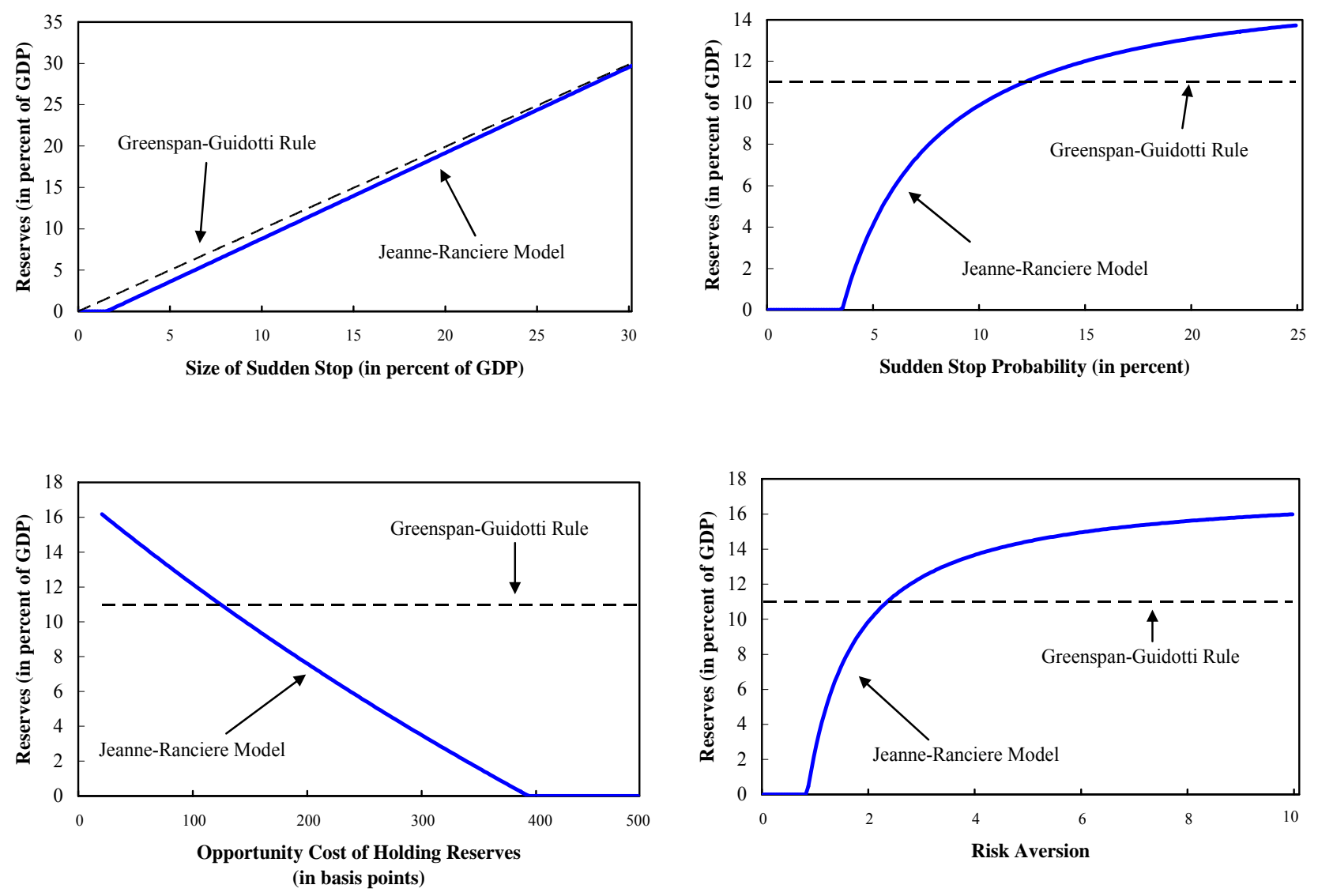

Source: Authors' computations. 
Figure 5. Reserves as a Share of GDP in Asia and Latin America, 1980-2003 (In percentage points of GDP)

Asia

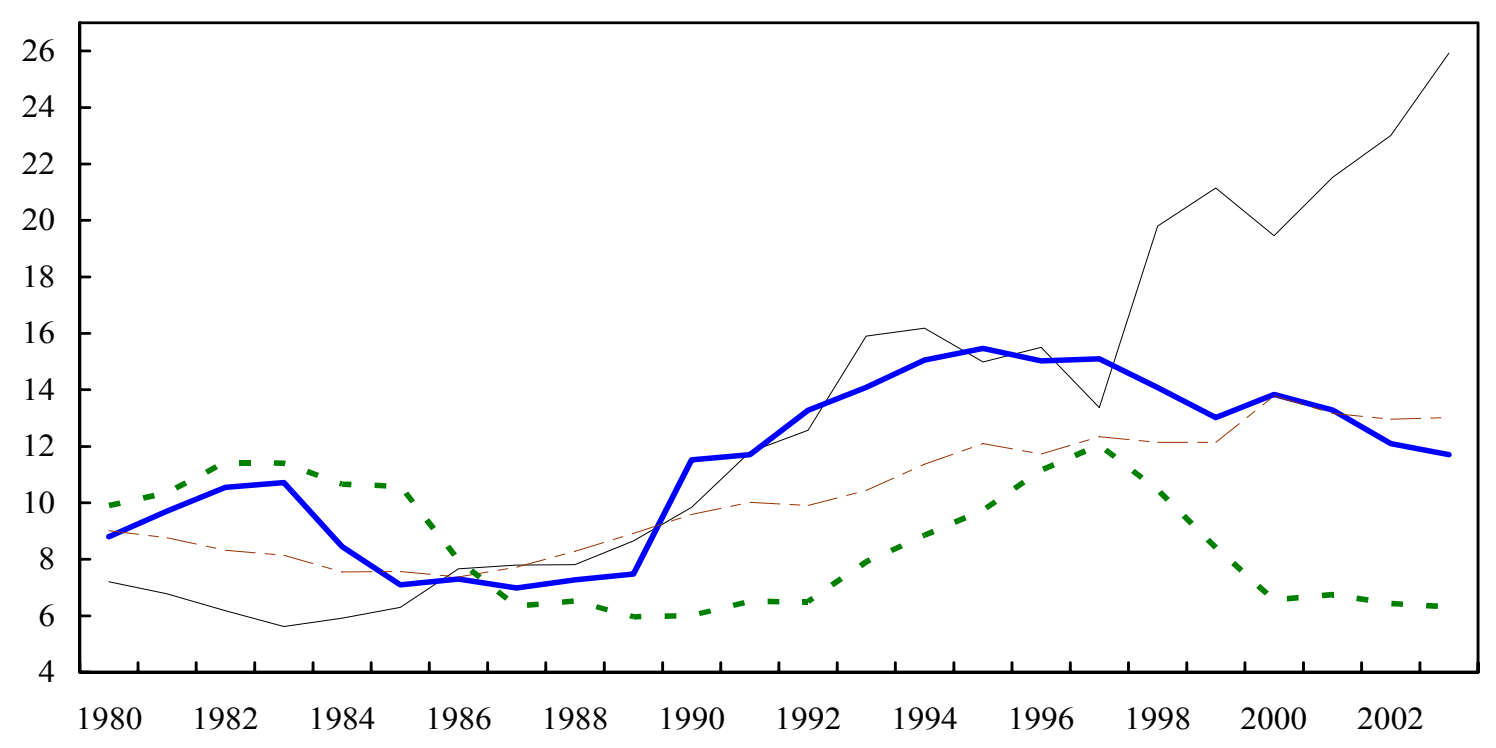

Latin America

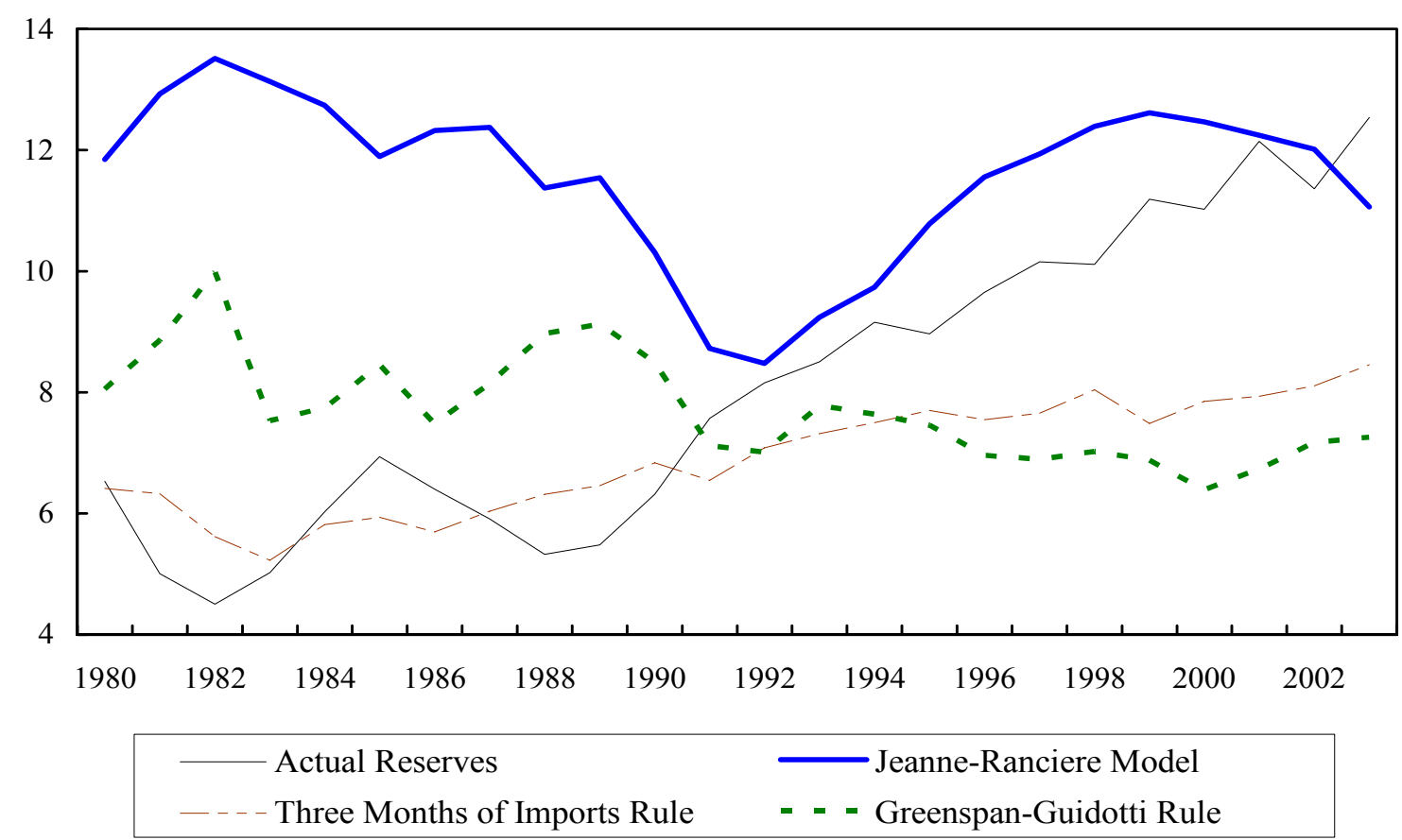

Source: Authors' calculations using data from IMF, International Financial Statistics, and World Bank, Global Development Finance.

Note: Total reserves minus gold (excludes IMF financing). 


\section{APPENDIX: COMPUTATIONS}

\section{Deriving Equation (16)}

Our assumptions on the dynamics of output and private external debt are summarized in the following equations,

$$
\begin{gathered}
Y_{t}^{b}=Y_{t}^{a}=(1+g)^{t} Y_{0}, \quad Y_{t}^{d}=(1-\gamma)(1+g)^{t} Y_{0} \\
L_{t}^{b}=\lambda(1+g)^{t} Y_{0}, \quad L_{t}^{d}=L_{t}^{a}=0 .
\end{gathered}
$$

Plugging these expressions and $R_{t-1}=\rho Y_{t}^{b}$ into equations (11) and (12) gives,

$$
\begin{gathered}
C_{t}^{b}=\left(1+\lambda-\frac{1+r}{1+g} \lambda-(\delta+\pi) \rho\right)(1+g)^{t} Y_{0}, \\
C_{t}^{d}=\left(1-\gamma-\frac{1+r}{1+g} \lambda+(1-\delta-\pi) \rho\right)(1+g)^{t} Y_{0} .
\end{gathered}
$$

Plugging these expressions into the first-order condition $\left(C_{t}^{d}\right)^{-\sigma}=p\left(C_{t}^{b}\right)^{-\sigma}$ gives equation (16).

\section{The Case with a Real Exchange Rate Depreciation}

The government's problem is now

subject to,

$$
R_{t}=\arg \max (1-\pi) u\left(C_{t+1}^{b}\right)+\pi u\left(C_{t+1}^{d}\right),
$$

$$
\begin{gathered}
C_{t+1}^{b}=Y_{t+1}^{b}+L_{t+1}^{b}-(1+r) L_{t}^{b}-(\delta+\pi) R_{t}, \\
C_{t+1}^{d}=(1-\gamma) Y_{t+1}^{b}-(1+\Delta Q)(1+r) L_{t}^{b}+(1+\Delta Q)(1-\delta-\pi) R_{t} .
\end{gathered}
$$

The first-order condition remains $\left(C_{t+1}^{d}\right)^{-\sigma}=p\left(C_{t+1}^{b}\right)^{-\sigma}$, with $p$ now given by

$$
p=\frac{(1-\pi)(\delta+\pi)}{\pi(1-\delta-\pi)(1+\Delta Q)}
$$

Manipulations of the first-order condition using equations (5) and (6) then give,

$$
\rho=\frac{1+\lambda+\gamma p^{1 / \sigma}+\lambda\left(p^{1 / \sigma}(1+\Delta Q)-1\right)(1+r) /(1+g)-p^{1 / \sigma}}{p^{1 / \sigma}(1+\Delta Q)(1-\delta-\pi)+\delta+\pi} .
$$




\section{REFERENCES}

Aizenman, Joshua, and Jaewoo Lee, 2005, “International Reserves: Precautionary Vs. Mercantilist Views, Theory, and Evidence," IMF Working Paper 05/198 (Washington: International Monetary Fund).

Aizenman, Joshua, and Nancy Marion, 2003, "The High Demand For International Reserves In the Far East: What is Going On?," Journal of The Japanese and International Economies, Vol. 17, pp. 370-400.

Beck, Thorsten, and Ross Levine, 2005, "Financial Structure Database," The World Bank, Washington, D.C.

Broner, Fernando, Guido Lorenzoni, and Sergio Schmukler, 2004, "Why Do Emerging Economies Borrow Short Term?", World Bank Policy Research Working Paper No.3389 (Washington: World Bank).

Bussière, Matthieu, and Christian Mulder, 1999, "External Vulnerability in Emerging Market Economies: How High Liquidity Can Offset Weak Fundamentals and the Effects of Contagion," IMF Working Paper 99/88 (Washington: International Monetary Fund).

Caballero, Ricardo J., and Stavros Panageas, 2004a, "Contingent Reserves Management: An Applied Framework," unpublished, MIT, Department of Economics.

— , 2004b, "Insurance and Reserves Management in a Model of Sudden Stops," unpublished, MIT, Department of Economics.

Dooley, Michael P., David Folkerts-Landau, and Peter Garber, 2004, "The Revived Bretton Woods System: The Effects of Periphery Intervention and Reserve Management on Interest Rates and Exchange Rates in Center Countries, "NBER Working Paper 10332 (Cambridge, Massachusetts: National Bureau of Economic Research).

Edwards, Sebastian, 2004, "Thirty Years Of Current Account Imbalances, Current Account Reversals and Sudden Stops," Staff Papers, International Monetary Fund, Vol. 51(10), pp.1-49.

Flood, Robert, and Nancy Marion, 2002, "Holding International Reserves In an Era of High Capital Mobility," IMF Working Paper 02/62 (Washington: International Monetary Fund).

Frenkel, Jacob, and Boyan Jovanovic, 1981, “Optimal International Reserves: A Stochastic Framework,” Economic Journal, Vol. 91, pp. 507-14.

Garcia, Pablo S., and Claudio Soto, 2004, "Large Hoarding of International Reserves: Are they worth it?" manuscript, Bank of Chile. 
Guidotti, Pablo, Federico Sturzenegger, and Agustin Villar, 2004, "On the Consequences of Sudden Stops," Economía, Vol. 4, No. 2, pp.171-203.

Hauner, David, 2005, “A Fiscal Price Tag for International Reserves,” IMF Working Paper 05/81 (Washington: International Monetary Fund).

International Country Risk Guide, 2005, “Political Risk Service”, New York, N.Y.

International Monetary Fund, 2003, “Are Foreign Exchange Reserves in Asia Too High?” World Economic Outlook, September, 2003, Chapter II, pp. 78-92.

Lane, Philip R., and Gian Maria Milesi-Ferretti, 2006, “The External Wealth of Nations Mark II: Revised and Extended Estimates of Foreign Assets and Liabilities, 1970-2004,” IMF Working Paper 06/69 (Washington: International Monetary Fund).

Morris, Stephen, and Hyun Song Shin, 1998, "Unique Equilibrium in a Model of SelfFulfilling Currency Attacks", American Economic Review, Vol. 88(3), pp. 587-97.

Quinn, Dennis, 2000, “Democracy and International Financial Liberalization”, manuscript, McDonough School of Business, Georgetown University.

Rancière, Romain, Aaron Tornell, and Frank Westermann, 2003, "Crises and Growth: A Re-evaluation”, NBER Working Paper No. 10073 (Cambridge, Massachusetts: National Bureau of Economic Research).

Reinhart, Carmen, and Kenneth Rogoff, 2004, “The Modern History of Exchange Rate Arrangements: A Reinterpretation,” Quarterly Journal of Economics, Vol. 119(1), pp.1-48.

Rodrik, Daniel, 2006, “The Social Cost of Foreign Exchange Reserves,” NBER Working Paper No. 11952 (Cambridge, Massachusetts: National Bureau of Economic Research).

—_, and Andrés Velasco, 2000, "Short-Term Capital Flows," Annual World Bank Conference on Development Economics, September, 1999”.

Zettelmeyer, Jeromin, 2000, "Can Official Lending Be Counterproductive in the Short Run?" Economic Notes, Vol. 29(1), pp.13-29. 